\title{
Bonded Labor and Serfdom A Paradox of Voluntary Choice
}

\author{
Garance Genicot \\ University of California at Irvine
}

Revised March 2001

\begin{abstract}
Among the oldest and most pervasive economic institutions are bonded labor and serfdom. While seemingly exploitative, both bonded labor and serfdom are often not imposed on the laborers but voluntarily chosen. It is generally the lack of suitable alternatives which makes workers opt for a life in servitude. This paper shows that the existence of these voluntary forms of servitude itself may restrain the laborers' opportunities so that they are left with no better alternative than bondage. Under these circumstances, government interventions banning servile institutions, by promoting the development of alternative options for the laborers, have the potential to substantially improve the condition of a large class of laborers.
\end{abstract}

JEL Classification Numbers: D40, C72, O10, J41, K31.

Key Words: implicit contract, bonded labor, interlinkage, credit, coercion.

I am particularly grateful to Kaushik Basu, Richard R Brooks, Stephen Coate, David Easley, Robert T. Masson, Ted O’Donoghue, Michael Waldman and two anonymous referees for their constructive comments. In addition, the paper greatly benefitted from seminar presentations at Cornell University, the University of California at Irvine, el Instituto Technológico Autonomo de Mexico, l’Université de Montréal, the Tinbergen Institute, and the World Bank. Please address correspondence to ggenicot@uci.edu. 
"Man is born free, but everywhere he is in chains," Rousseau.

\section{Motivation}

Bonded labor and similar practices (e.g., peonage, debt slavery, serfdom, attached labor, contract labor) have been prevalent throughout the history of humankind and can be found in many parts of the world even today. Interestingly, bonded labor is ex-ante voluntary. In the case of debt-bondage, a tenant or debtor voluntarily places himself in a servile position, even though he may have little or no choice in the matter. Just as a serf is tied to his master by apparently voluntary acts of fealty, the bonded laborer is a technically free wage laborer whose state of servitude may be terminated on payment of the debt (see Watson [1976], p. 7). So, although once bonded a worker is unfree, the act of choosing to be bonded is usually one freely made to avert acute poverty or starvation.

The incidence of bonded labor and serfdom has been amply documented throughout history and in all parts of the world. ${ }^{1}$ Note that slavery itself has been reported to be voluntary in many instances. Perhaps less well-known is the extent to which these institutions persist in more recent times. A report of the Temporary Slavery Commission of the League of Nations in 1925 brings evidence of bonded labor in all of South America, the Philippines and parts of Africa, and states that the practice was widespread all over Africa and Asia, (Macmunn [1974], pp. 250-2). The presence of bonded labor was reported in Indonesia, the Philippines, Malaysia, Siam, Burma, colonial Laos and Cambodia (Lasker [1944], pp. 113-67); in Thailand (Turton [1976], pp. 272-3); and in Ethiopia and Sudan (Ennew [1981], p. 261). In the United States, some Southern states held trials

1 Debt slavery is a well-known phenomenon in ancient civilization. Aristotle himself described the situation of debt bondsmen in Athens, various forms of voluntary slavery and bonded labor existed in Rome of the Antiquity and in Ptolemaic Egypt, and the Judaic law distinguished explicitly chattel and debt slaves as foreigners and Jews respectively [Ennew (1981), p. 63]. 
for peonage as recently as in the 1970s (See Daniel [1973]). In 1996, the US imposed economic sanctions on Pakistan for its use of child and bonded labor. In addition, beyond the most noted examples, one needs only to observe present-day societies to find a multitude of labor contracts aiming at limiting workers mobility.

In recent decades, most governments have explicitly banned bonded labor. India passed the Bonded Labor System Abolition Ordinance in October 1975 after a century and a half of unsuccessful attempts to wipe out bonded labor, and Pakistan issued its Bonded Labour System Abolition Act in March 1992. Supporters of a ban typically rely on either moral and humanitarian arguments or on the limited rationality of the laborers. For instance the Indian government in its ordinance for abolishing bonded labor states:

"The existence of bonded and forced labor in large parts of our country was an ugly and shameful feature of our social life which cried for urgent attention. Being totally out of tune with our new socio-economic order, this evil and pernicious practice had to be wiped out altogether by bringing forward an appropriate legislation." [Bonded Labor System Abolition Ordinance 1975]

In contrast, the Roman Law and the US common law typically rely on the concept of "unconscionability" to invalidate bonded labor contracts. ${ }^{2}$

Opponents to legal interventions aimed at curtailing bonded labor use revealed preference arguments and say that these moral arguments are misplaced. If the laborers are rational individuals maximizing their utility and that they freely agree to enter into servitude, they must be better off. Many find the voluntary nature of this choice puzzling and somehow disturbing, but these labor relationships typically concern very poor workers whose set of opportunities appears so limited that these contracts may well represent their best option. A number of studies report that, while far from being well treated, bonded laborers often had a more enviable life than they would have had

$2 \quad$ See Craswell and Swartz (1994). 
otherwise. ${ }^{3}$ Moreover, whenever a ban on bonded labor was not strictly enforced, a large proportion of these laborers voluntarily returned to their master. ${ }^{4}$ They conclude that limiting the availability of bonded labor practices actually hurts the very people it intends to help since it results in a welfare loss for bonded laborers.

However, the above line argument is unconvincing and mistaken. It hinges on the assumption that the set of choices that an individual faces is exogenously determined. But in reality the range of possibilities existing for a given person at a given time is endogenous. Within a given choice set, an agent's choice maximizes his utility but ruling out some of his choices may in effect open new opportunities for him. This is the paradox of voluntary choice to which the title of this paper refers.

This paper demonstrates that a ban on bonded labor can increase the welfare of workers even under assumption of pure rationality. The argument goes as follows. In many situations, the existence of bonded labor hinders the development of welfare enhancing credit opportunities for the laborers. In these cases, a ban on bonded labor, by stimulating the development of credit opportunities, actually increases laborers' utility. The present paper builds a model of labor and credit markets which corroborates this claim. ${ }^{5}$

The argument is two-fold. First, the asymmetry of enforcement power between landlords and credit institutions has as consequence that the latter may refuse credit to the poor because of the

3 Describing the bonded labor relationships in South India, Lumsden wrote in a letter of 1825: "I believe the (debt) slaves to be more comfortable than the free portion of their respective castes." Half a century later this statement is unequivocally repeated: "Hali (bonded laborers) are still, as a rule, better off than those of their clan who are nominally free labourers," [Gazetteer of the Bombay Presidency 1877, Vol. 2, Surat and Broach, Bombay, p.201]. Breman [1993] writes (on p.59) "... instead of wishing to terminate the relation as soon as they could, both parties aimed at continuing it as long as possible."

4 On freed bonded laborers reentering into bondage, see Kloosterboer [1960].

5 Other arguments in favor of a ban on bonded labor could involve non-linear discounting, or endogenous preferences like Schaffner (1995). 
availability of bonded labor. The lack of collateral, asymmetries of information, and ineffective judicial institutions widespread in rural and less developed countries' economies render the cost of establishing and enforcing explicit credit contracts exorbitant. This is why credit contracts for assetless peasants are often based on implicit (or self-enforcing) agreements in which the loss of future credit opportunities provides borrowers with incentives not to voluntary default on their current loans. ${ }^{6}$ In this environment, the existence of bonded labor contracts increases the value of reneging on a simple implicit credit contract by providing the peasant who does not repay a local credit institution with an alternative source of credit. Hence, bonded labor has the potential to render implicit contracts unenforceable, thereby preventing assetless peasants access to formal credit. This argument fits into an expanding literature on implicit contracts in organizational economics, in particular Baker et al.'s [1994, 1997] comparison between implicit and explicit contracting, although this paper differs by introducing direct competition between both types of contracts. ${ }^{7}$

Second, if the local credit institutions are competitive or limit the interest rate they charge while the landlord has some monopoly power, as typical in village economies, access to loans from credit institutions increases the laborers' welfare. In such situations, a ban on bonded labor makes laborers better off. Far from stating that a ban on bonded labor is always desirable, this paper demonstrates that such situations may arise, and that as a result legislative interventions are worth considering. The analysis also shows how the laborer's productivity is important in determining how a ban on bonded labor would affect the laborers' welfare.

In addition, this paper illustrates the extent to which the distinction between the imposition of an institutional form of servitude and the limitations placed on individual choice by the lack of

\footnotetext{
$6 \quad$ Without denying the existence of honesty, guilt or norms, the only way a lender knows for certain that a borrower will repay is when the contract is self-enforcing, that is when it is in the borrower's interest to do so.

7 See MacLeod and Malcomson [1989] and Baker, Gibbons and Murphy [1994, 1997].
} 
opportunities is rather blurred. This point is particularly well phrased in a judgement of the Supreme Court of India in a bonded labor case: ${ }^{8}$

"Any factor which deprives a person of a choice of alternative and compels him to adopt one particular course of action may properly be regarded as 'force' and if labor or services is compelled as a result of such 'force' it would be 'forced labor'."

The analysis can easily encompass other cases of freely chosen servitude. A contract may be deemed exploitative when a party uses its power to restrain the set of alternatives available to another party, so as the latter has no better choice than to agree upon a contract very advantageous to the first party. This concept is along the same lines as the notions of power used by Basu [1986], Hirshleifer [1991], and Bardhan [1991b]. ${ }^{9}$

The rest of the paper proceeds as follows. The next section summarized the relevant literature. Section 3 determines the equilibria of the labor and credit markets in the absence and the presence of bonded labor. Section 4 assesses the welfare implications of a ban on bonded labor. Then, section 5 relaxes some key assumptions of the model. Finally, section 6 concludes the analysis.

\section{Previous Research}

Bhaduri [1973] models "semi-feudal economies" characterized by perpetual indebtedness of sharecroppers to landlords and the absence of formal credit markets. Assuming the tenant's initial balance of commodity, after repayment of previous debt, to be lower than the subsistence level of consumption and a very high propensity to consume result in a stationary state in which the tenant is caught

8 Supreme Court's judgement dated 18.09.1982 in Peoples Union for Democratic Rights and Others (W.P. No 8143 of 1981).

9 This notion of power lies in the capacity of coercing an individual into accepting a trade that make the latter worse off than he would be in the status-quo (Hirshleifer [1991]). Other contributions to triadic relationships and the concept of power are Akerlof [1976] and Naqvi and Wemhöner [1995]. 
in perpetual indebtedness. In such economies, technological improvements that reduces the tenant's need for consumption loans are often undesirable to the landowner because the decrease in revenue from usury outweighs the benefits from increased productivity of the land.

A few studies on tied-labor agreements (year-round or longer term labor contracts) show situations in which profit-maximizing employers in competitive markets have an incentive to offer such contracts to some workers. In Bardhan [1979], employers offer tied-labor agreements to avoid the cost of recruiting workers during the peak season. Bardhan [1983] reinterprets 'tied-labor' contracts as an example of implicit contracts to which the results of the labor literature hold. ${ }^{10}$ Such contracts provide risk-averse laborers with insurance against the wide swings in income due to fluctuations in demand for their services, and risk-neutral landlords with assured cheap labor during the peak season. In Eswaran and Kotwal [1985], tied-labor agreements provide workers with incentives to work effectively during the slack season. Mukherjee and Ray [1995] use Stiglitz and Shapiro [1984]'s argument to justify the coexistence of a casual labor and mutually advantageous labor-tying agreements. If the information on the laborers' history is imperfect casual labor must exist in equilibrium so as to prevent the tied laborers to renege on their contracts when casual market wages are high. However, Bardhan [1991] expresses concern that such models "cover up the basic, often ugly, power relations involved in the phenomena under study," (Bardhan [1991a] p.238).

Introducing another possible source of credit than the landlord, Srinivasan [1989] studies a tenant's choice between bonding himself to the landlord or borrow from a local credit institution. In his model, the local institution provides credit up to a ceiling at the same interest rate as the landlord. If the tenant borrows from the credit institution but fails to repay the amount due, he is assumed to be denied access to future loans not only from the institution but also from the landlord. If he 10 For a good review of the labor literature on implicit contracts, see Rosen [1986]. 
fails to repay in a bonded labor contract, he would loose his income but is ensured renewal of credit by repaying through labor services. In addition there is an upper limit on the size of loans from the credit institution due to enforcement problems while there is no ceiling on the loans from the landlord who has more enforcing power. Hence, the tenant most often chooses bonded labor and a ban on bonded labor reduces the welfare of bonded laborers. The assumption that a peasant is never allowed to switch from one institution to the other is essential to these results. With homogeneous agents however, there is no reason to believe that the landlord would refuse a bonded labor contract to a peasant who is denied loans from a credit institution.

The present paper investigates the choice of a peasant between bonded labor contracts and formal loans, but also the strategic interaction between the landlord and the local credit institutions. The distinctive feature of the present paper lies in the fact that the peasant's mobility between the two sources of credit is not restricted. This considerably affects the above results and reveals a power relation. Assetless peasants still often choose to enter into bonded labor and this decision is voluntary, but this choice results from the landlord's power to rule out alternative credit opportunities for the laborers. Hence in many cases there are made worse off by the existence of bonded labor. This has considerable welfare implications, and provides a possible rationale for banning bonded labor.

\section{The Model}

Consider a village economy with competitive labor and credit markets and a large number of identical, infinitely long-lived, assetless peasants. ${ }^{11}$ Time is divided into periods, called years, them-

11 The GPF-NLI Survey carried out in ten states of India in 1978 estimated that $63 \%$ of bonded laborers have no land at all and 66\% have no big animal, (Dingwaney et al. [1986], p.2). 
selves composed of two sub-periods of equal length, the lean season and the peak season. A peasant's preferences are assumed to be representable by a utility function defined over consumption of a single good and additively separable over time. Let a peasant's utility in a given period be $u\left(c_{1}, c_{2}\right)=U\left[c_{1}\right]+\delta U\left[c_{2}\right]$, where $\delta \in(0,1)$ is his discount factor per season (half a period), $c_{i}$ is the peasant's consumption in season $i, i \in\{1,2\}$, and $U: \Re \Re_{+} \rightarrow \Re$ is twice continuously differentiable, strictly increasing and strictly concave, i.e. $U^{\prime}[c]>0$ and $U^{\prime \prime}[c]<0$. The peasants, who are endowed with one unit of labor each season and no other source of income, supply their labor inelastically. Wages are 0 in the lean season and $w>0$ during the peak season. There is no uncertainty but no savings or storage opportunity such that credit is valuable. ${ }^{12}$

These assumptions aim at representing the main characteristics of rural environments where bonded labor prevailed. Agricultural production is seasonal. Harvests occur in yearly cycles which require large amounts of labor for half the year, but little during the remainder of the year. ${ }^{13}$ As a consequence, wages and employment in the area are high during the peak season and wages are low during the lean season when unemployment is high. ${ }^{14}$ Savings opportunities are very limited. The income fluctuations and the low income during part of the year render credit valuable to the peasants. "The serious problem of survival from harvest to harvest can only be overcome by borrowing for consumption" (Bhaduri [1973] p. 122).

Being assetless, the peasants have no formal collateral. Hence, credit contracts from local credit institutions are implicit and based on the reputation of the peasant. If the peasant fails to repay the

\footnotetext{
12 The absence of savings is not crucial to the model. Assuming good savings opportunities but reintroducing uncertainty in the wage would mean that some credit is desirable.

13 By an estimate made during 1974-75, a worker in the rural area could get only 215 days of wage employment a year. For the rest of the 150 days, he had practically no employment (Dingwaney et al. [1986], p. 8). For more evidence on the fluctuations in agricultural employment over the year, see also Prasad [1976], p.1269.

14 "Especially in agricultural occupations during the non-seasonal periods, wage rates tend to fall much below the minimum...” (Prakash [1990], p.78).
} 
amount due, including interest rate $r$, all lending institution (that are assumed to share information costlessly) deny him credit from then on into the future. This is indeed an equilibrium strategy for the banks as will be shown explicitly but for now treat this as an assumption. The alternative to the local institutions is for the peasants to work as bonded laborers for the landlord. In a bonded labor contract, a laborer who receives an advance from his landlord during the lean season has to work for that landlord during the peak season. ${ }^{15}$ This is the sense in which the landlord has a better enforcement power than the credit institutions since the landlord can directly deduct the amount due from the laborer's wage in the peak season. ${ }^{16}$

In order to evaluate the welfare implications of a ban of bonded labor, the following two subsections study the equilibrium in the labor and credit markets first in the absence of bonded labor, then in its presence. The concept of equilibrium used here is subgame perfection and, although many equilibria can be supported by the model (as typically in infinitely repeated games), the focus is here on equilibria supported by simple trigger strategies. In a world where bonded labor is not allowed, the laborer is free to work elsewhere in the peak season and landlords have no advantage compared to credit institutions. ${ }^{17}$ Hence in this first subsection, we consider the local credit institutions as the only source of credit.

\subsection{Credit Markets When Bonded Labor Does Not Exist}

The credit institutions choose an interest rate $r$ and a set of loan sizes $\mathcal{B} \subseteq \Re^{+}$that they would agree on lending in order to maximize their profit given an opportunity cost per unit of capital of

\footnotetext{
15 "He [the bonded laborer] lives on the house-site of his master and is satisfied with the cooked food supply twice in his house or the grain wage." (Prakash [1990], p.47)

16 The present paper is concerned only with the enforcement issue. Other problems of moral hazard or adverse selection that may arise, although interesting, are beyond the scope of the study.

17 Indeed the landlord is likely to face a higher cost of capital than the credit institutions. For other potential reasons explaining interlinked credit and labor contracts, see Braverman and Stiglitz [1982] and Bardhan [1991a].
} 
$1+\rho$. Laborers then decide on the amounts to borrow and whether to repay their dues.

A casual laborer who borrows $B$ for consumption at an interest rate $r$ from a credit institution in the beginning of each period, and repays its due at the harvest enjoys a utility of $U[B]+\delta U[w-$ $B(1+r)]$ each period. Note that a discount rate of $\delta$ per season implies a discount rate per period of $\delta^{2}$. Hence, the laborer's lifetime discounted utility is :

$$
V(B, r)=\frac{1}{1-\delta^{2}}\{U[B]+\delta U[w-B(1+r)]\} .
$$

Hence, abstracting from any enforcement problem and given an interest rate $r$, the optimal loan size $\widetilde{B}(r)$ a laborer would want is

$$
\widetilde{B}(r)=\arg \max _{B \geq 0} V(B, r)
$$

The uniqueness and positiveness of $\widetilde{B}$ are direct consequence of $V_{1}(0, r)>0$ and the fact that $V$ is strictly concave in $B, V_{11}(B, r)<0$.

By concavity of the maximand, if this laborer faced a credit ceiling of $\bar{B}$, he would choose to borrow $B^{*}(r)$ where

$$
B^{*}(r)=\min \{\widetilde{B}(r), \bar{B}\}
$$

Now, at a given interest rate $r \geq \rho$, a credit institution would concede a loan of size $B$ to a laborer if and only if the latter has both the ability and the willingness to repay in the second season. The ability to repay simply requires that

$$
B(1+r) \leq w,
$$

while the willingness to repay demands that the short-run gain for the laborer of defaulting on his loan be less than the relative long-run value of his relationship with the credit institution. This is 
exactly what the following inequality, hereafter referred to as the repayment constraint, says: ${ }^{18}$

$$
U[w-B(1+r)]+\delta V(B, r) \geq U[w]+\delta V[0, r],
$$

where $V(B, r)$ is defined in (1). The discounted utility from repaying the amount due and still having access to the same loan at each subsequent period (the left-hand side of inequality (5)) must be higher than the utility from not repaying the loan and being denied any further credit from a lending institution (the left-hand side of inequality (5)). ${ }^{19}$ Using (1) in (5), one can easily check that the repayment constraint is equivalent to

$$
\begin{gathered}
U[w-(1+r) B]+\delta U(B) \geq U[w]+\delta U[0] \\
\text { or } \quad\{U[B]-U[0]\}-\frac{1}{\delta}\{U[w]-U[w-(1+r) B]\} \geq 0
\end{gathered}
$$

This last inequality implies that we can define a function

$$
H(B, r) \equiv\{U[B]-U[0]\}-\frac{1}{\delta}\{U[w]-U[w-(1+r) B]\}
$$

which, given an interest rate $r$, takes positive values over the range of loan sizes $B$ satisfying (5).

Hence, the repayment constraint is

$$
H(B, r) \geq 0
$$

Note that the willingness to pay is a sufficient condition for the ability to repay (i.e., (7) implies (4)). In other words, a peasant qualifies for a loan of size $B$ if and only if $H(B, r) \geq 0$.

The credit ceiling faced by a peasant at any credit institution, denoted by $\bar{B}(r)$, can be defined

\footnotetext{
18 We make the tie-breaking assumption that, if indifferent between repaying or not, the peasant always repays.

19 It worth emphasizing that loans are used only for consumption purposes and not invested. This is supported by the aforementioned GPF-NLI Survey that reveals that $55 \%$ of the loans taken by bonded laborers accounts for domestic expenditure like food clothes, medical treatment or other basic needs of the family. Only about $25 \%$ accounts for festive occasions including death rites, celebration on childbirth, marriages, etc. (Dingwaney et al. [1986], p. 9).
} 
as the maximum loan size which satisfies the repayment constraint (7) for an interest rate of $r$ :

$$
\bar{B}(r)=\max \{B \mid H(B, r) \geq 0\}
$$

$H(B, r)$ has the following properties: $(i) H(0, r)=0$ for all $r ;(i i) H$ is decreasing in $r$ and concave in $B, H_{2}(B, r)<0$ and $H_{11}(B, r)<0 ;{ }^{20}$ and $(i i i)$ for sufficiently large loans, the repayment constraint is not satisfied $H(B, r)<0$ (for instance $H\left(\frac{w}{1+r}, r\right)<0$ ). These properties guarantee the existence and uniqueness of $\bar{B}(r)$ for all $r$, and imply that $\bar{B}(r)$ is decreasing in $r$.

If $\bar{B}(\rho)>0$ then there exists a strictly positive loan size that satisfies the repayment constraint for some $r \geq \rho$. The condition under which $\bar{B}(\rho)>0$ is the following:

$$
H_{1}(0, \rho)=U^{\prime}[0]-\frac{(1+\rho)}{\delta} U^{\prime}[w]>0
$$

This inequality is trivially satisfied if the marginal utility at 0 consumption is very large, as seems natural, or if the discount rate is sufficiently high. Note that if $U(0)$ is very low then $H(\widetilde{B}) \geq 0$ is ensured, and the laborer is not credit constrained. Let's assume for now that $(A 1)$ holds but we will be relax this assumption later on.

Proposition 1 characterizes the second-best equilibrium in this economy.

Proposition 1 : The above economy has a perfect equilibrium in which $i$ ) credit institutions offer loans of size $\mathcal{B}=[0, \bar{B}(\rho)]$ at interest rate $r=\rho$ to casual laborers who have never defaulted and refuse to lend to others; $i i$ ) the peasant work as casual laborers and borrow an amount $B^{*}=B^{*}(\rho)$ in each lean season; and $i$ ) they repay the total amount due, $B^{*}(1+\rho)$, after each harvest if no loan has ever been conceded to defaulters, and otherwise default.

Proof. Let $r=\rho$ in (7). By construction, any loan of size $B \in[0, \bar{B}(\rho)]$ satisfies the repayment (7) and it is the laborers' best response to repay the amount due after each harvest and to default

20 Indeed $U^{\prime}>0$ and $U^{\prime \prime}<0$ imply that $H_{2}(B, r)=-\frac{B}{\delta} U^{\prime}[w-B(1+r)]<0$ and $H_{11}(B, r)=U^{\prime \prime}[B]+$ $\frac{1}{\delta} U^{\prime \prime}[w-B(1+r)](1+r)^{2}<0, \forall B \geq 0$. 
on any other loan size. Among this interval a loan of size $B^{*}(\rho)$, as defined in (3), maximizes the laborer's utility since he indeed repays.

A credit institution would never offer a credit contract, a line of credit summarized by its ceiling $\bar{B}$ and an interest rate $r$, that does not satisfy the repayment constraint (7). Among these $(\bar{B}(\rho), \rho)$ is clearly an equilibrium for all credit institutions. Indeed, any other credit contract $\left(B^{\prime}, r^{\prime}\right)$ satisfying (7) and yielding a non-negative profit must be such that $B^{\prime} \leq \bar{B}\left(r^{\prime}\right)$ and $r^{\prime} \geq \rho$. If $B^{\prime}<\bar{B}\left(r^{\prime}\right)$ then there is another contract $\left(B^{\prime \prime}, r^{\prime}\right)$ where $B^{\prime}<B^{\prime \prime} \leq \bar{B}\left(r^{\prime}\right)$ that yields at least as much profit to a credit institution. And if $r^{\prime}>\rho$ then a credit institution could attract all borrowers and increase its profit by slightly reducing its interest rate and offering $\left(B^{\prime}, r^{\prime \prime}\right)$ where $\rho<r^{\prime \prime}<r^{\prime}$ (note that this contract still satisfies (7) since $\bar{B}(r)$ is decreasing in $r$ ). Hence, competition drives the interest rate down to $r=\rho$ and the credit institutions offer a line of credit $[0, \bar{B}(\rho)]$.

It just remains to check that the threat of exclusion from the loan market in case of default is credible. This is ensured by the fact that renewing a loan to a defaulter causes all other laborers to believe they can default without penalty. ${ }^{21}$

\subsection{Credit Markets When Bonded Labor Contracts Are Allowed}

A bonded labor contract is modeled here as a combination of both a labor and a credit contract over the whole period. The bonded laborer tills the landlord's land in exchange for some fixed levels of consumption $S_{1}$ and $S_{2}$ in the first and the second season respectively. All the harvest goes to the landlord. For ease of notation, we assume that landlords and peasants have the same discount rate per season $\delta$. In this case, it is optimal for a landlord to provide his bonded laborers with the same consumption of at both seasons, $S_{1}=S_{2}=S$. Therefore $S$, hereafter called the 'term' or

21 A model of borrowing for production where default leads to exclusion from the capital market is presented by Allen (1983). 
'size' of the contract, fully characterizes a bonded labor contract. To realize the wide range of labor relationships concerned by this paper, it is important to notice that very different combinations of wages, loan and interest rate result in a same schedule of consumption provided at each season.

In a first time, let's assume that the landlord can commit on a bonded labor contract and therefore model the competition between the landlord and the credit institutions as a Stackelberg game. Section 5 examines the consequences of relaxing this assumption, but we take it as given for now. The game is as follows. The landlord chooses a bonded labor contract $S$ that he offers to all laborers at any time. The credit institutions then decide on a set of available loan sizes $\mathcal{B}$ and an interest rate $r$ to offer to the laborers in the lean season. Finally, peasants choose between being bonded laborers or casual laborers. In the latter case, they also decide on the amount to borrow from a local credit institution.

A peasant who defaults on a loan from a credit institution retains the option of accepting a bonded labor contract. This option increases the temptation to default on the credit institutions, thereby reducing the range of loans that satisfy the repayment constraint. Hence, the existence of bonded labor affects the loans that credit institutions are willing to lend to assetless laborers.

First, consider a peasant's choices given a line of credit $\mathcal{B}$ and interest rate $r$ at the credit institutions and a term of bonded labor $S$ offered by the landlord. The utility of a casual laborer who borrows $B$ each lean season and repays its dues is $V(B, r)$ defined in (1). Hence, in the absence of enforcement problem, if he chose to be a casual worker, a peasant would borrow

$$
B^{*}(r)=\arg \max _{B \in \mathcal{B}} V(B, r)
$$

and would enjoy a lifetime utility of $V\left(B^{*}, r\right)$. As bonded laborer, he would consume $S$ each 
season. His discounted lifetime utility as bonded laborer is an increasing and concave function of $S$,

$$
V_{L}(S)=\frac{1}{1-\delta} U[S]
$$

A peasant maximizes his utility when choosing between casual and bonded labor, such that his utility is

$$
v(B, S, r)=\max \left\{V_{L}(S), V(B, r)\right\}
$$

Let's assume that when indifferent the peasant becomes a bonded laborer. This tie-breaking assumption allows the landlord's problem below to be a maximization over an closed set and, as we will see in more details, does fundamentally not affect any result.

Now let's look at the credit institutions' choices. Taking the size of the prevailing bonded labor contract as given, credit institutions maximize profit. Given an interest rate $r \geq \rho$, a credit institution would agree on lending any amount in $\mathcal{B}$ to a laborer if only if for any $B \in \mathcal{B}$ the laborer would be both able and willing to repay. The repayment constraint requires the utility a laborer receives from repaying the institution, and thereby accessing the same amount of credit each period, to exceed the utility the laborer receives from defaulting and being denied any future credit from lending institutions. Unlike the previous section, however, the utility of defaulting needs to account for the availability of bonded labor. The repayment constraint is ${ }^{22}$

$$
U[w-(1+r) B]+\delta v(B, S, r) \geq U[w]+\delta v(0, S, r) .
$$

where $v(B, S, r)$ is defined in (11) and accounts for the option a peasant has to become bonded

$2 \overline{\text { This formulation assumes that } S}<w$ since the laborer waits for the next period to bond himself. It is clearly always true at the equilibrium. The landlord would not give more per season to peasants than the output they produce. Note again that the repayment constraint is sufficient for the ability to repay, $w-B(1+r) \geq 0$, to be satisfied. 
laborer. For our purpose, it is convenient to rewrite the repayment constraint in terms of a function $G$ that takes positive values only over the range of loans that satisfy (12). Naturally, $G$ is a function of $B, r$, and $S$ :

$$
G(B, S, r) \equiv\left(1-\delta^{2}\right)\{v(B, S, r)-v(0, S, r)\}-\frac{1-\delta^{2}}{\delta}\{U[w]-U[w-(1+r) B]\} \geq 0
$$

Clearly, $G$ is decreasing in $S$ since $V_{L}(S)$ is a strictly increasing function of $S$.

Pick a value for $r$ and keep it constant. $V_{L}(S)$ is continuous and strictly increasing, $V_{L}(0) \leq$ $V(0, r)$, and for sufficiently high values of $S$ we have $v(0, S, r)=V_{L}(S)>V(0, r)$. Moreover $V(0, r)$ is independent of $r$. Hence, there is a unique $\underline{S} \geq 0$ such that $v(0, \underline{S}, r)=V_{L}(\underline{S})=V(0, r)$. At $\underline{S}$, a peasant is just indifferent between a bonded labor $\underline{S}$ and casual labor with no access to credit. For any $S<\underline{S}$, peasants never become bonded laborers and $G(B, S, r)=H(B, r)$ as defined in (6). In contrast, whenever $S \geq \underline{S}$ a peasant refused credit from lending institutions would become a bonded laborer. The repayment constraint for any $S>\underline{S}$ is thus

$$
G(B, S, r)=U[B]-(1+\delta) U[S]-\frac{1-\delta^{2}}{\delta} U[w]+\frac{1}{\delta} U[w-(1+r) B] \geq 0
$$

Figure 1 maps $G$ as a function of $B$ for different values of $S$. Above the threshold $\underline{S}$, to higher values of $S$ correspond lower $G$ curves in Figure 1.

In addition to being decreasing in $S$ and in $r, G$ is strictly concave in $B, G_{11}(B, S, r)<0{ }^{23}$ $G(0, S, r) \leq 0 \forall S, r$; and for sufficiently large loan sizes $B$ it is negative $G(B, S, r)<0$ (for instance $\left.G\left(\frac{w}{1+r}, S, r\right)<0\right)$. These properties imply that, for given $S$ and $r$, the loans sizes for which the repayment constraint is satisfied is a closed interval. Let $\underline{B}(S, r)$ and $\bar{B}(S, r)$ be respectively

$2 \overline{23}$ These are direct consequences of the positive monotonicity and concavity of the utility function. Indeed $G_{2}(B, S, r)=$ $-\frac{B}{\delta} U^{\prime}[w-B(1+r)]<0$ and $G_{11}(B, S, r)=U^{\prime \prime}[B]+\frac{1}{\delta} U^{\prime \prime}[w-B(1+r)](1+r)^{2}<0, \forall B \geq 0$. 


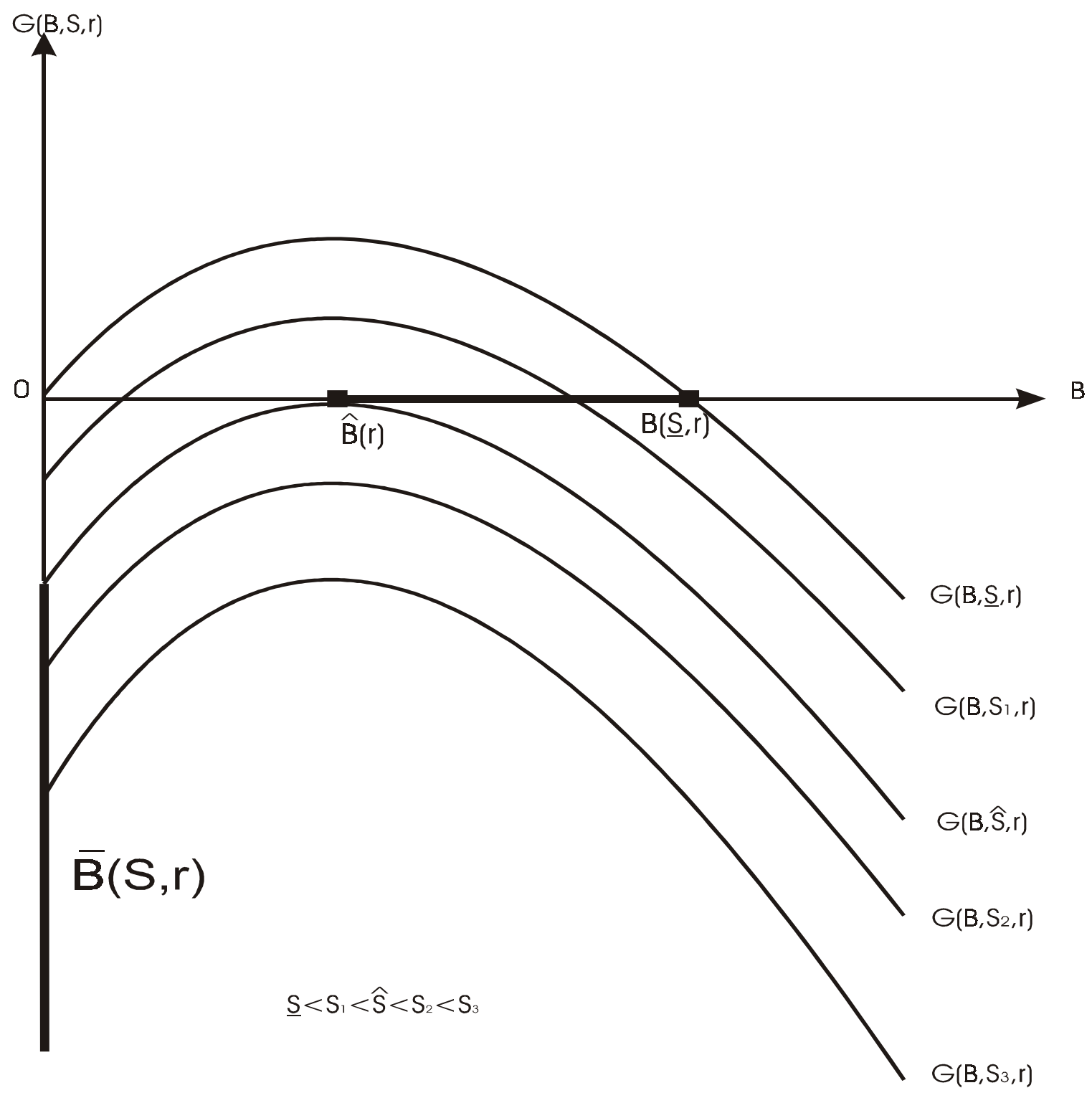

Figure 1: Repayment Constraints 
the minimum and the maximum loan sizes that satisfy the repayment constraint or 0 if no such values exist:

$$
\begin{aligned}
& \underline{B}(S, r)=\left\{\begin{array}{l}
\min \{B \mid G(B, S, r) \geq 0\} ; \text { if such a } B \text { exists } \\
0 \text { otherwise. }
\end{array}\right. \\
& \bar{B}(S, r)=\left\{\begin{array}{c}
\max \{B \mid G(B, S, r) \geq 0\} ; \text { if such a } B \text { exists } \\
0 \text { otherwise. }
\end{array}\right.
\end{aligned}
$$

By the same argument as made in the previous section, in equilibrium the competition between the credit institutions drives the equilibrium interest down to their opportunity cost of capital $r=\rho$, and the line of credit they offer to casual laborers is $[\underline{B}(S, \rho), \bar{B}(S, \rho)]$. A line of credit $[\underline{B}(S, r), \bar{B}(S, r)]$ is clearly optimal since the repayment constraint is satisfied and laborers can choose the loan size that maximizes their utility within this range. Now, any higher interest rate than $\rho$ would be slightly undercut by a credit institution that would then serve the whole demand. To simplify notation, in the remaining of the paper we set the interest rate at $r=\rho$, unless otherwise stated, and let $\underline{B}(S)=\underline{B}(S, \rho)$ and $\bar{B}(S)=\bar{B}(S, \rho)$.

It is worth noticing that $G(B, S, r)$ is separable in $(B, r)$ and $S .{ }^{24}$ This property, together with the strict concavity of $G$ in $B$, implies that, for any given $r$, the loan size that maximizes $G(B, S, r)$ is unique and independent of $S$. This loan size, $\widehat{B}(r)$, is defined by

$$
G(\widehat{B}(r), S, r) \geq G(B, S, r) \text { for all } B \geq 0, \forall S, r
$$

and let $\widehat{B}=\widehat{B}(\rho)$. Note that $\widehat{B}>0$ follows from assumption $(A 1)$ since the latter implies that $G_{1}(0, S, \rho)>0 \forall S$.

\footnotetext{
24 Indeed, $G(B, S, r)=X(B, r)-Y(S)-Z$, where $X(B, r)=U[B]+\frac{1}{\delta} U[w-B(1+r)], Y(S)=\max \{U(0)+$ $\delta U(w),(1+\delta) U(S)\}$, and $Z=\frac{1-\delta^{2}}{\delta} U[w]$.
} 
Pick a term of bonded labor $S$. If the repayment constraint is satisfied at $\widehat{B}, G(\widehat{B}, S, \rho)>0$, then $\widehat{B}$ must belong to the interval of loan sizes that satisfies the repayment constraint, $\underline{B}(S)<$ $\widehat{B}<\bar{B}(S)$, and the casual worker's credit ceiling, (16), is strictly positive. If $G(\widehat{B}, S, r)=0$ then $\widehat{B}$ is the unique loan size that satisfies the repayment constraint and $\underline{B}(S)=\bar{B}(S)=\widehat{B}$. Lastly, if $G(\widehat{B}, S, r)<0$ then it is clearly so for any loan size. The repayment constraint cannot be satisfied for any $B, G(B, S, r) \leq 0 \forall B \geq 0$ and $\underline{B}(S)=\bar{B}(S)=0$.

The following proposition proves that the minimum loan sizes never binds.

Proposition $2 \widetilde{B} \geq \underline{B}(S, \rho)$ where $\widetilde{B}=\arg \max _{B \geq 0} V(B, \rho)$.

Proof. Clearly, for any $r \underline{B}(S, r) \leq \widehat{B}(r)$, where $\widehat{B}(r)$ is defined in (17). Hence, if we show that $\widetilde{B}(r) \geq \widehat{B}(r)$ then we have proved proposition 2 . Let's compare $\widehat{B}(r)$ that is implicitly defined by $U^{\prime}[\widehat{B}]=\frac{(1+r)}{\delta} U^{\prime}[w-(1+r) \widehat{B}]$ with $\widetilde{B}(r)$ which is such that $U^{\prime}[\widetilde{B}]=(1+r) \delta U^{\prime}[w-(1+r) \widetilde{B}]$. It follows from $\delta \in(0,1)$ that $\frac{(1+r)}{\delta}>(1+r) \delta$, and therefore that $\widetilde{B}(r) \geq \widehat{B}(r) \geq \underline{B}(S, r)$.

As a consequence, the equilibrium strategy of the credit institutions can be summarized by the credit ceiling $\bar{B}(S)$ and the competitive interest rate $\rho$ that are offered to casual laborers during the lean season.

Naturally, the credit ceiling $\bar{B}(S)$ is non-increasing in $S$ the term of bonded labor.

Proposition $3: \bar{B}\left(S_{1}\right) \leq \bar{B}\left(S_{2}\right)$ for all $S_{1}>S_{2} \geq 0$.

Proof. We noticed earlier that $G(B, S, r)$ is separable in $(B, r)$ and $S$, and that it is decreasing in $S$. It follows that if $S_{1}>S_{2},\left\{B \mid G\left(B, S_{1}, \rho\right) \geq 0\right\} \subset\left\{B \mid G\left(B, S_{2}, \rho\right) \geq 0\right\}$. Hence, $\max \{B$ $\left.\mid G\left(B, S_{1}, \rho\right) \geq 0\right\} \leq \max \left\{B \mid G\left(B, S_{2}, \rho\right) \geq 0\right\}$. Therefore, $\bar{B}\left(S_{1}\right) \leq \bar{B}\left(S_{2}\right)$.

Figure 2 illustrates a laborer's credit ceiling $\bar{B}$ as a function of the prevailing term of bonded labor contract $S$. 


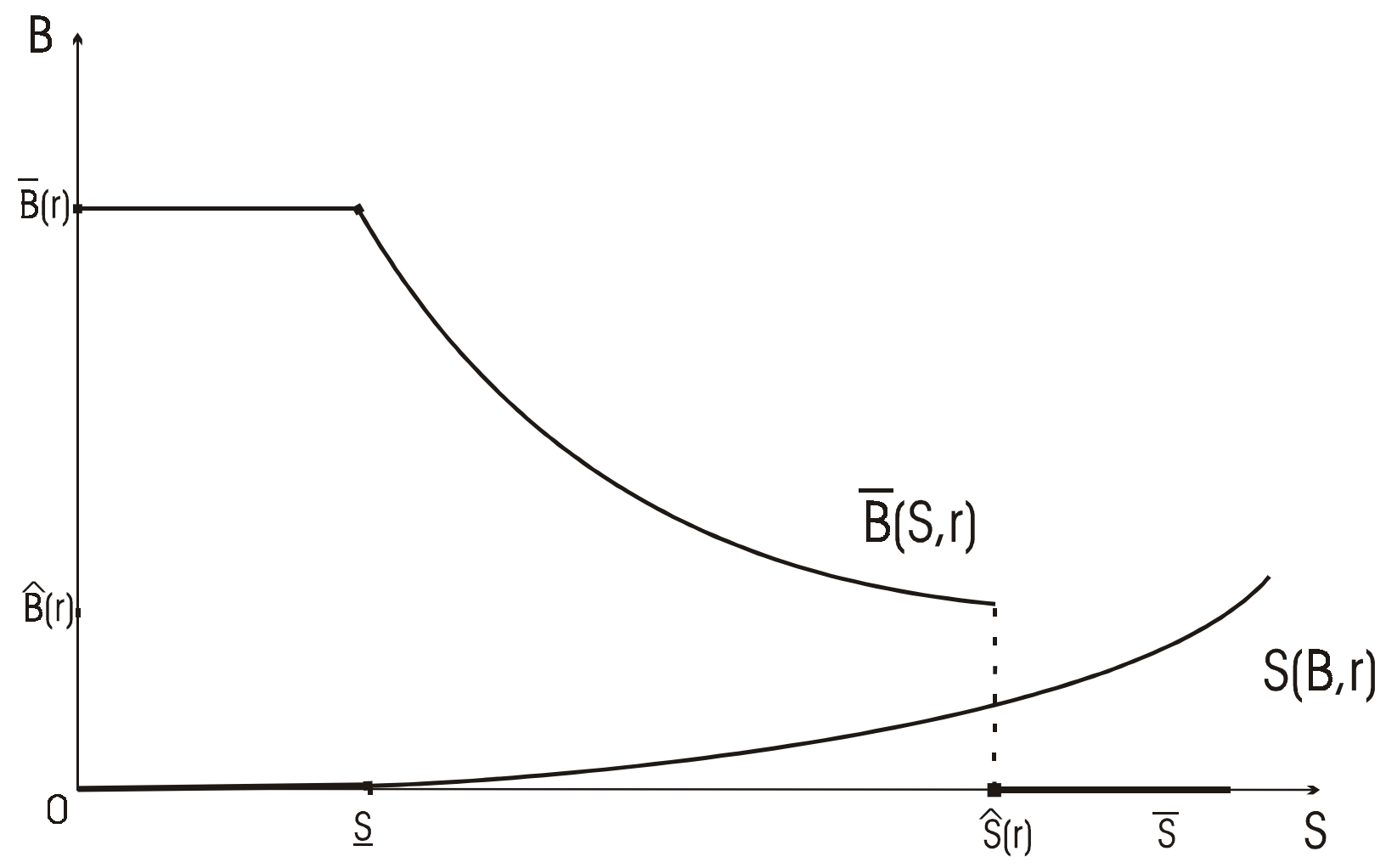

Figure 2: Credit Ceiling and Bonded Labor Contracts 
Finally, consider the landlord's strategy. He provides his bonded laborers with a level of consumption $S$ per season, and at the harvest he receives the product of the crop. The landlord chooses the term bonded labor contract $S$ that maximizes his discounted profit subject to the laborers' participation given the line of credit available to them at the credit institutions. Hence, the landlord's problem is:

$$
\begin{aligned}
\operatorname{Max}_{S \geq 0} \pi(S) & =\frac{1}{1-\delta^{2}}\{w-(1+\delta) S\} \\
\text { subject to } V_{L}(S) & \geq V(B, \rho) \text { and } B=B^{*}(S, \rho) .
\end{aligned}
$$

The profit of the landlord being linearly decreasing in $S$, we can focus on the constraints. Let $\bar{S}$ be the highest profitable term of bonded labor $\bar{S}=\frac{w}{1+\delta}$. The landlord will offer $\widehat{S}$, where

$$
\widehat{S}=\min \left\{S \mid V_{L}(S) \geq V\left(B^{*}(S, \rho), \rho\right)\right\}
$$

is the lower $S$ that satisfies laborers' participation constraint, if such term of bonded labor leaves him with a non-negative profit that is if $\widehat{S} \leq \bar{S}$. For the problem to be interesting, we assume that $\underline{S} \leq \bar{S}$ (recall that $\underline{S}$ is the term of the bonded labor contract just sufficient to induce the peasant's participation in the absence of any loans from credit institutions). Otherwise, the landlord would never want any bonded laborers and the situation would be identical to the previous section.

The size of the bonded labor contract chosen by the landlord, $S^{*}$, is then

$$
S^{*}=\min \{\widehat{S}, \bar{S}\}
$$

and we can distinguish two cases depending on whether $\widehat{S}$ is greater or smaller than $\bar{S}$.

Before doing so, it is useful to map the term of bonded labor which leaves a laborer indifferent between bonded labor and casual labor as a function of the amount of credit of $B$ available to the 
casual laborers, $S(B) \equiv\left\{S \mid V_{L}(S)=V(B, \rho)\right\}$. Figure 2 illustrates this participation constraint $S(B)$. At any loan size that is lower than his optimal loan, a laborer's utility as a casual laborer increases with the loan size he is able to obtain, and therefore the term of bonded labor would need to increase to keep him indifferent. In other words $S^{\prime}(B)>0$ for all $B<\widetilde{B}$. On the contrary, for loans sizes at or above his optimal loan higher loan sizes does not affect or reduce his utility and therefore the term of bonded labor that would keep him indifferent decreases, $S^{\prime}(B) \leq 0$ for all $B \geq \widetilde{B} \cdot{ }^{25}$

Pick a specific loan size $B$ from a credit institution. Given $B$ the landlord would improve the term of the bonded labor contract as long as $V(B, \rho) \geq V_{L}(S)$ holds and that it is profitable to him, $S<\bar{S}$. An increase in $S$ has a direct effect by increasing the value of the bonded labor contract $V_{L}(S)$. But in addition it has an indirect effect. A higher term for the bonded labor contract increases the value of the alternative for a defaulting peasant, thereby lowering substantially the credit ceiling at the bank $B^{*}(S)$, and consequently the utility $V\left(B^{*}(S), \rho\right)$ of being a casual laborer if the ceiling is binding $B^{*}(S)=\bar{B}(S)$. Hence we are looking for a fixed point.

The following two propositions further characterizes the landlord's offer (20). First, Proposition 4 states that, if a peasant becomes a bonded labor, he necessarily does not have access to any credit at the local institutions. Then Proposition 5 identifies the method to actually evaluate (19).

Proposition 4 : If a bonded contract $S$ is agreed upon, it must be the case that $B^{*}(S)=0$.

Proof. Let's prove it by contradiction. Assume that the peasant has accepted a bonded labor contract whose term is $S$ and that $B^{*}(S)>0$. On the one hand, the peasant having chosen to be a bonded laborer implies that $V_{L}(S)>V\left(B^{*}\right)$. On the other hand, a positive line of credit from a credit

25 The exact slope of the bonded laborer's participation constraint is given by $\frac{d S}{d B}=\frac{U^{\prime}[B]-(1+r) \delta U^{\prime}[w-(1+r) B]}{(1+\delta) U^{\prime}[S]}$ which is positive (strictly negative) for all $B \leq \widetilde{B}(B>\widetilde{B})$. 
institution, $B^{*}(S)>0$, means that the repayment constraint (13) has to be satisfied. That is, $G\left(B^{*}, S\right)=\left\{V\left(B^{*}\right)-V_{L}(S)\right\}-\frac{1}{\delta}\left\{U[w]-U\left[w-B^{*}(1+r)\right]\right\} \geq 0 .{ }^{26}$ A necessary condition for this inequality to hold is clearly $V\left(B^{*}\right)>V_{L}(S)$. Hence, this contradicts the assumption made that the peasant has chosen to enter into bondage for the landlord.

Proposition 5 : $\widehat{S}$ is the unique bonded labor contract $S$ such that $G(\widehat{B}, S)=0$, with $\widehat{B}$ defined in (17).

Proof. As noticed earlier, $\widehat{B}$ is independent of $S$ and $G$ is continuous and decreasing in $S$. Moreover, $\lim _{S \rightarrow \infty} G(\widehat{B}, S)<0$, and $G(\widehat{B}, \underline{S})>0$ follows from $(A 1)$. Hence, there is a unique bonded labor

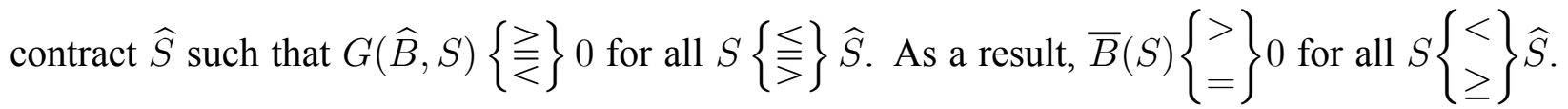
Proposition 3 proved that, to be accepted, a bonded labor contract must be such that $\bar{B}(S)=0$. In addition, the landlord's profit is strictly decreasing in $S$. Therefore, when profitable, the landlord would offer the smallest bonded contract the laborers would participate in, that is $\widehat{S}$.

After having determined the strategies of the landlord, credit institutions and peasants, we can now characterize the resulting equilibrium. An equilibrium is $(i)$ the choice of peasants between casual and bonded labor corresponding to (11) given their line of credit; $(i i)$ the term of bonded labor the amount they borrow from the credit institutions during the lean season: $\left(B^{*}(r)\right.$ as defined in (9) if casual laborers and 0 if they become bonded laborers; (iii) the credit institutions best response: an interest rate $r=\rho$ and a credit ceiling $(\bar{B}(S))$ for all possible terms of bonded labor; and finally $(i v)$ the term of bonded labor chosen by the landlord $S^{*}$ as defined in (20).

Depending on the parameters, two possible equilibrium outcomes can be distinguished.

\section{Equilibrium 1: $\widehat{S} \leq \bar{S}$}

$\overline{26 \quad S \geq \underline{S} \text { follows from } V_{L}(S)>V}\left(B^{*}\right)$ and $B^{*}>0$. Hence, for these values the relevant repayment constraint is (14). 
In this equilibrium, the landlord offers a bonded labor contract $S^{*}=\widehat{S}$. As illustrated by the credit institutions' best response in Figure 2, this means that the line of credit available to casual workers is null, $B^{*}\left(S^{*}\right)=0$. The peasants do not have access to any loans as casual laborers and therefore become bonded laborers since $V_{L}(\widehat{S})>V(0, \rho)$. Moreover, $\widehat{S}<\bar{S}$ means that a contract $\widehat{S}$ is profitable for the landlord.

This equilibrium is especially interesting since the following stylized facts apply. In rural areas, the casual workers' income is highly variable and assetless peasants are denied loans from local credit institutions. As a result, these peasants voluntary accept bonded labor contracts and, as the evidence reported in the introduction suggest, bonded laborers have a better life than the one they would have had as casual laborer.

To understand the element of exploitation in bonded labor contracts, however, it is important to realize that the existence of bonded labor prevents assetless peasants to access loans. It is the landlord's strategy to push the peasant into a situation where he has no better choice than to bond himself. The discontinuity of the credit ceiling function $\bar{B}(S)$ in Figure 2 reveals the power of the landlord and the inherent competitive disadvantage of implicit contracts. For a loan size to satisfy the repayment constraint it must bring not only more utility to laborers than bonded labor but also sufficiently more to satisfy the repayment constraint. The utility from a loan whose size lies within the range of values $(0, \widehat{B})$ is strictly higher than the utility from the bonded labor contract $\widehat{S}$, but is not sufficiently higher to satisfy the repayment constraint. Hence, credit institutions refuse these loans to peasants.

Clearly, assuming that when indifferent, a peasant chooses casual over bonded labor would not fundamentally affect our results. The landlord would need to increase his offer by a very small 
amount to induce the laborer's participation and the equilibrium concept would be an $\varepsilon$-equilibrium. The fact that this would not affect the equilibrium outcome can be seen from the discontinuity in the credit institution's best response in Figure 2.

\section{Equilibrium $2: \widehat{S}>\bar{S}$}

By providing his bonded laborers with more than $\bar{S}$ per season, the landlord would earn a negative profit. He would therefore never do so. On the other hand, terms of bondage smaller than or equal to $\widehat{S}$ are insufficient to rule out alternative credit opportunities for the laborers. Hence, in this equilibrium the landlord offers $S^{*}=\bar{S}$ and the peasants choose to be casual laborers. They borrow $B^{*}(\bar{S})$ each lean season from a local credit institution, and repay the amount due in the following season. Bonded labor is not actually observed. However, it is important to see that such equilibrium is unlikely. For such equilibrium to exist, the landlord must have an opportunity cost of capital relatively high compared to that of the credit institutions. Yet, the landlord has the option to use his land as a collateral and therefore borrow from a credit institution at the competitive interest rate $r=\rho$. In this case, the landlord's discount factor is close to $\frac{1}{1+\rho}$, and it is easy to see that only equilibrium 1 exists. ${ }^{27}$

\section{Welfare Effect of a Ban on Bonded Labor.}

The welfare effect of a ban on bonded labor can now be assessed. The laborers' productivity, that is the casual laborers' wage $w$, in the peak season is an important element in evaluating the welfare impact of a ban since $w$ affects the amount of credit for which casual laborers qualify in

$27 \quad$ The landlord chooses the amounts to give at each season, $S_{1}$ and $S_{2}$, that maximize his profit conditional on the peasant's participation. These amounts are such that $U^{\prime}\left[S_{1}\right]=(1+r) \delta U^{\prime}\left[S_{2}\right]$. The optimal level of credit for a peasant solves $U^{\prime}[B]=(1+r) \delta U^{\prime}[w-B(1+r)]$. Hence, the landlord can always propose up to the optimal level of credit and this necessarily rules out any access to credit for the peasant. Therefore, equilibrium 1 would prevail if the landlord has perfect access to credit. 
the absence of bonded labor. Let $\widehat{w}$ be the threshold productivity level below which assumption (A1) does not hold. If casual wages during the harvest are lower than $\widehat{w}$, then assetless peasants would not access loans from the credit institution even if bonded labor was illegal. Laborers accept bondage for $\underline{S}$, where $\underline{S}$ leaves them indifferent between bonded and casual labor. The bonded labor contract corresponds to the certainty equivalent and the landlord benefits from the surplus generated by smoothing the laborers' consumption. This contract is similar to the tied-labor agreements in Bardhan [1983] and does not reduce the laborers' utility.

In contrast, in any economy where $w>\widehat{w},(A 1)$ is satisfied and $\bar{B}>0$. The analysis developed in Section 3 applies. Note the more patient the peasants the lower $\widehat{w}$. In equilibrium 1 , peasants become bonded laborers and receives a lifetime utility of $V_{L}\left(S^{*}\right)$. Naturally, they prefer bonded labor rather than not having any credit at all, but this reservation utility can be very low if $U(0)$ is very small. And although the laborer freely enters into bondage, it is the existence of bonded labor itself which, by reducing the peasant's alternative sources of credit, drives him to agree to it. Recall from section 3.1 that, if a ban on bonded labor is enforced, a peasant's lifetime utility is

$$
V\left(B^{*}, \rho\right)=\frac{1}{1-\delta^{2}}\left\{U\left[B^{*}\right]+\delta U\left[w-B^{*}(1+\rho)\right]\right\}
$$

where $B^{*}=\min \{\widetilde{B}(\rho), \bar{B}(\rho)\}>0$. Hence, the peasants are necessarily made strictly better off by a ban on bonded labor since $\left.V_{L}\left(S^{*}\right)<V \widehat{((B)}, \rho\right) \leq V\left(B^{*}, \rho\right)$. In equilibrium 2 , bonded labor is actually not observed. Casual laborers borrow an amount $B^{*}(\bar{S})$ in the beginning of each period and repay after harvest. However, if peasants are credit constrained at that level, that is $B^{*}(\bar{S})<\widetilde{B}$, they are strictly worse off as compared to a situation in which bonded labor is illegal and therefore would benefit from a ban. Indeed, the potential existence of bonded labor suffices to reduce the 
line of credit available to the peasants since $\bar{S}>\underline{S}$.

These results have important implications for the role and mode of government interventions. Consider a rural area in which bonded labor prevails and where there is no other access to credit for assetless peasants. Observing the situation, the government or some development agency may want to promote the improve credit opportunities for the poor. However, it is unlikely that landlords do not react. Our model suggests how relatively easy it is for a landlord to increase slightly the term of bonded labor they offer thereby ruling out all credit opportunities for the laborers. By doing so, landlords prevent the development of a formal credit market without much improvement in the condition of their laborers. In such a situation, a ban on bonded labor, if effectively enforced, has the potential to allow the development of a credit market and to substantially improve the condition of a large class of laborers.

When describing bonded labor, people usually concentrate on the laborers' debt. However, as noticed earlier, different combination of wages, loan sizes and interest rates can result in the same amount of consumption for the bonded laborer. Even though a bonded laborer's debt may accumulate over time, given the options available to him, the laborer would prefer to be bonded. Many studies provide evidence of the rather fictitious nature of the debt. For instance, Breman [1993] writes:

"As farm servant they did not receive any remuneration, but they were entitled to credit. Under these circumstances it was hardly relevant that their debt increased in this way. More important was that their subsistence was assured in an economy of scarcity... The debt was rather fictitious is its character. Not only was the repayment merely theoretical on account of the hali (or bonded laborer)'s minimal remuneration, 
but it was not envisaged by either of the parties," (Breman [1993], p.44).

Hence, the fact that the laborer locks himself, for a certain period of time, in a relationship with a specific employer may be more important to characterize the labor relationships concerned here than the size of the debt itself. ${ }^{28}$ This allows us to understand the similarities between bonded labor and other labor practices to which this model applies. An instance of such a practice, which is also banned in most places, is known as 'contract labor' in which the laborer is tied for a period of time (generally one to five years), and can choose freely to renew the contract at the end of it.

Before closing this section we illustrate this more concretely with an example.

\section{Example :}

Let $u(x)=\ln (x)$, and assume that wages fluctuate between 0 in the lean season and $w=2$ in the peak season.

Note that, in the absence of any other source of credit, a casual laborer's repayment constraint would be satisfied for any loan $B$ that gives him strictly positive consumption at both seasons, $0<B<\frac{2}{1+r}$, since $\ln (0)=-\infty$. Hence, a casual laborer in the absence of bonded labor would not be credit constrained, $B^{*}=\widetilde{B}$, and the bonded labor contract that leaves laborers indifferent between bonded labor and casual labor without credit $\underline{S}$ is 0 . For all $S \geq 0$, we can therefore write

\footnotetext{
28 For more evidence, see Singh [1947] who describes very well the relationship in these terms, "The debt of a harwaha [bonded laborer] is a fictitious asset. These people never take their debt seriously, for they know that, their incomes being grossly inadequate, redemption of a debt is out of the question. They look upon the money they are able to borrow from the Zamindar [landlord] as their income. And the Zamindar too does not consider the money advanced to a harwaha a loan. He does not want the debt to be redeemed" (Singh [1947], p.134). Prasad [1976] reports similar evidence, "It is known to both parties that it is beyond the means of the 'deficit' household to repay either the loan or the interest in full, even in the long run. Still the loans are advanced. The whole operation, in fact, means that the poor peasant receives only 'subsistence.' Part of it is paid in cash or kind or both. The rest is paid as a loan so as to enforce the debt-bondage on the poor-peasantry with a view to appropriate almost the entire surplus value" (Prasad [1976] , p.1271).
} 
the repayment constraint (12) as

$$
G(B, S, r) \equiv \ln [B]-(1+\delta) \ln [S]-\frac{1-\delta^{2}}{\delta} \ln [2]+\frac{1}{\delta} \ln [2-(1+r) B] \geq 0
$$

Maximizing this expression over the loan sizes $B$ gives us

$$
\widehat{B}=\frac{\delta w}{(1+\delta)(1+r)}
$$

and solving for $\widehat{S}$ such that $G(\widehat{B}, \widehat{S}, r)=0$ we find that

$$
\widehat{S}=w\left(\frac{\delta}{1+r}\right)^{\frac{1}{1+\delta}}\left(\frac{1}{1+\delta}\right)^{\frac{1}{\delta}}
$$

Assuming the following values for the discount rate the credit institutions' opportunity cost of capital, $\delta=.9$ and $\rho=.11$, and using the above equaltion, we find that $\widehat{S}=.88$. This is smaller than the maximum profitable term of bonded labor $\bar{S}=.95$ such that the landlord offers $\widehat{S}$ to laborers. In this equilibrium, casual laborers would be denied any credit from the credit institutions and as a result peasants would become bonded laborer for the landlord. The peasants utility is

$$
v(\widehat{B}, \widehat{S}, r)=\frac{1}{1-\delta} \ln (\widehat{S})=-1.28
$$

Now, we can compare this with the benchmark case (in the absence of bonded labor). The loan size that maximizes a casual laborer's utility, $V(B, \rho)=\frac{1}{1-\delta^{2}}\{\ln [B]+\delta \ln [2-B(1+\rho)]\}$, is $\widetilde{B}=\frac{2}{(1+\delta)(1+\rho)}=.95$. It follows from $B^{*}=\widetilde{B}$ that the lifetime discounted utility a peasant would enjoy in the absence of bonded labor is

$$
V\left(B^{*}, \rho\right)=V(.95, .11)=-.54
$$

Clearly the existence of bonded labor has significantly reduced the laborer's utility (by 137\%). 
Now assume the same parameters as in the previous example at the exception of the credit institution's opportunity cost of capital $\rho=.06$.

In this case, we find that $\widehat{S}=.9$ and $\bar{S}=.47$. Hence $\widehat{S}$ is larger than $\bar{S}$ and the situation corresponds to equilibrium 2. The cost of capital is larger for the landlord compared to the credit institutions. Bonded labor contracts that generate the peasants' participation are not profitable to the landlord and bonded labor is therefore not observed.

\section{Discussion on Commitment and Contestability}

We have assumed so far that the landlord can commit to the bonded labor contract that he offers to all peasants. It is this precise assumption that allows the landlord's offer to affect the repayment incentive of the laborers, and consequently to reduce their access to credit from the credit institution. This is because the peasants can default on their current loan and become bonded laborers the following period. Let us consider the impact of relaxing this assumption.

The landlord knows that he is the only source of credit for a peasant who defaulted from a credit institution. Hence once a peasant has defaulted, the only term of bondage a landlord, who knows the default and could not commit, would offer is $\underline{S}$. Recall that $\underline{S}$ is the unique bonded labor contract $\underline{S} \geq 0$ that leaves the peasant indifferent between bonded labor and no credit at all, $V_{L}(\underline{S})=V(0, \rho)$. The credit institutions being aware of this, the relevant repayment constraint for a loan of size $B$ from a credit institution is $G(B, \underline{S}, \rho)=H(B, \rho) \geq 0$, and the casual laborers' credit ceiling is unaffected by the availability of bonded labor. The ceiling is thus $\bar{B}$, as defined in (8), and the effective loan is $B^{*}=\min (\bar{B}, \widetilde{B})$, defined in (3). The landlord's best response $S^{*}$ is then the term of bondage just sufficient to induce the laborers' participation, that is a contract which 
yields at least as much utility to the bonded laborers than to be a casual worker and have access to loans of size $B^{*}$ at each period $V_{L}\left(S^{*}\right)=V\left(B^{*}, \rho\right)$. Such a contract is generally profitable to the landlord when the laborers are credit constrained, $B^{*}<\widetilde{B}$, and thus bonded labor would prevail in the economy. ${ }^{29}$ It is important to realize that now peasants are made better off, or at least never worse off, by the availability of bonded labor.

Yet, it is likely that the landlord would try to develop a commitment device since it is his inability to commit not to drive a peasant who has defaulted to his reservation utility that drives the above result. Moreover, relaxing the structure of the model has striking implications.

Assume the landlord can still not commit on a bonded labor contract but can, as seems reasonable, make an offer to the peasants during the peak season. The landlord can propose an amount $M$, called the "bribe" hereafter, to a peasant who has taken a loan at a local credit institution at the condition that he does not repay the credit institution and becomes a bonded laborer. The landlord strategy is thus a triplet $\left(S_{N}, S_{D}, M\right)$, where $S_{N}$ is the term of bondage offered to the laborer if he never defaulted from a local credit institution; $S_{D}$ is the term of the offer to the laborer if he did default; and $M$ is the bribe or payment made to a laborer in the peak season if he borrowed from a credit institution.

Taking the possibility of a bribe into account, the following repayment constraint summarizes credit institutions' requirement for a loan of size $B$ taking the landlord's strategy as given:

$$
G\left(B, S_{D}, M\right) \equiv \delta\left\{V(B)-\max \left\{V_{L}\left(S_{D}\right), V(0)\right\}\right\}-\{U[w+M]-U[w-B(1+r)]\} \geq 0
$$

where as before $r=\rho$.

$2 \overline{9}$ It is necessarily the case if landlords have the same opportunity cost of capital as credit institutions. 
The difference in discounted utility between having access to loans of the same size in the future and be denied any further credit must be higher than the short term gain from not repaying the loan and receiving the bribe. Consequently, casual laborers face the following credit ceiling at the credit institutions:

$$
\bar{B}(M, S)=\left\{\begin{array}{c}
\max \{B \mid G(B, M, S) \geq 0\} \text { if exists } \\
0 \text { otherwise. }
\end{array}\right.
$$

The landlord's best response for a peasant who has not defaulted is

$$
S_{N}(B)=\min \left[\bar{S},\left\{S \mid V_{L}(S) \geq V(B)\right\}\right],
$$

where $\bar{S}=\frac{w}{(1+\beta)}$.

To a casual laborer who borrowed from a credit institutions, the landlord offers in the peak season a bribe

$$
\begin{gathered}
M=\min \{\widehat{M}, \bar{M}\} \\
\text { where }\left\{\begin{array}{c}
\widehat{M}=\min \left\{M \mid G\left(B, M, S_{D}\right) \leq 0\right\} \\
\bar{M}=\left[w-S_{D}(1+\beta)\right] \frac{\delta}{1-\delta^{2}}
\end{array}\right.
\end{gathered}
$$

The landlord offers the minimum amount necessary to make the laborer default on his current loan $\widehat{M}$, as long as this leaves a positive profit to the landlord $\widehat{M} \leq \bar{M}$.

And, as argued in the beginning of this section, the bonded labor contract that the landlord offers a laborer who did default is

$$
S_{D}(B)=\underline{S},
$$

since the latter does not have access to the credit institutions anymore.

The game is characterized by one of the following three equilibria. In the first equilibrium, characterized by $\widehat{M}<\bar{M}$, the threat of the landlord paying the amount $\widehat{M}$ necessary to rule out the 
peasant's credit opportunities is credible. Credibility in this context means that paying this amount would leave the landlord with a positive profit. As a consequence, credit institutions refuse to lend money to assetless casual laborers, and peasants agree upon a bonded labor contract as low as $\underline{S}$. This result is related to the concept of contestability. To see this, the key is to realize that the landlord never actually pays the bribe $M$. The mere fact that, if a laborer had access a loan, it would be the landlord's best response to pay the bribe prevents the credit institutions to give credit to the laborers. Hence, the latter become bonded laborer for the landlord and have a lifetime utility of $V_{L}(\underline{S})$.

The second and third equilibria are characterized by $\widehat{M} \geq \bar{M}$. It is not profitable for the landlord to make the payment necessary to induce a borrower to default on his current loan. Hence, the landlord has to offer a contract that yields more utility to the laborers than their transactions with a credit institution. This case reverts to the discussion made in the beginning of this section, and whether the peasants bond themselves or not, they cannot be worse off from the existence of bonded labor contracts.

\section{Conclusion}

This paper develops a model in which peasants choose between bonded labor and casual labor. Landlords and local credit institutions compete with each other on the credit market. When bonded labor is allowed their enforcement technologies differ. Bonded laborers agree to work exclusively for their landlord over the period. Hence, the landlord can subtract the amount due directly from the laborer's wage. Local credit institutions on the other hand have to rely on implicit agreements in which the threat of losing future credit opportunities prevents borrowers from defaulting on 
their loans. The possibility of entering into bondage, even if not very attractive, harms assetless peasants' access to credit by improving their options in case of default. In fact, landlords set the terms of bonded labor such that peasants are denied credit from the local credit institutions and voluntary choose bonded labor. In such case a ban on bonded labor may be deemed desirable since it would result in the development of welfare enhancing credit opportunities for the peasants.

This paper is primarily concerned with bonded labor in the setting of a rural village economy. However, the main result, that the existence of an institution can prevent the development of another, applies to a wide range of situations. Implicit contracts based on the threat of their own termination are to be found everywhere and this study highlights their inherent competitive disadvantage. This disadvantage follows directly from the fact that the feasibility of an implicit contract hinges on its own value relative to the best existing alternative. Hence, strategies aimed at rendering an implicit contract infeasible benefit from a leverage effect and are likely to be successful. This conclusion is relevant to any situation where implicit and explicit contracts coexist. ${ }^{30}$

This analysis has also important policy implications. In recent years, policy recommendations have started to recognize the necessity of taking into account the existence of an informal sector when designing public intervention in general, and credit programs in particular. However, it should be highlighted that it is not only the existence of the informal sector that should enter into the policy maker's consideration but also this sector's strategic response to the intervention or program. This paper also illustrates the major role that legislation can play. By modeling explicitly how curtailing free choice can enhance welfare, this paper provides a justification to the existence of ban on bonded labor in most countries.

30 One wide area of application among many is the development of supranational organizations or regulations. Individual countries benefit from direct enforcement mechanisms while supranational institutions needs to rely on implicit contracts. This should have important implications in international law or finance for example. 
Finally, this paper alludes to the question of what constitutes coercion and what constitutes free choice. Many contracts and transactions observed in the world appear "exploitative." However, in models with perfect foresight and rationality, all exchanges are voluntary. It is then hard to define coercion. In our example, realizing that it is in the landlords' interest to strategically restrain the choices available to laborers such that they voluntary accept bonded labor, makes one aware of how dim is the distinction between the limitations placed on personal choice by the lack of opportunities and the imposition of an institutional form of servitude. 


\section{Bibliography}

[1] Akerlof, G. (1976), 'The Economics of Caste and the Rat Race and Other Woeful Tales,' Quarterly Journal of Economics 90, pp. 599-617.

[2] Allen, Franklin (1983), 'Credit Rationing and Payment Incentives,' Review of Economic Studies L, pp. 639-46.

[3] Baker, George, Robert Gibbons and Kevin J. Murphy (1994), 'Subjective Performance Measures in Optimal Incentive Contracts Firm,' mimeo.

[4] Baker, George, Robert Gibbons and Kevin J. Murphy (1997), 'Relational Contracts and the Theory of the Firm,' Quarterly Journal of Economics 109, pp. 1125-56.

[5] Bardhan, Pranab K. (1979), 'Wages and Unemployment in a Poor Agrarian Economy: A Theoretical and Empirical Analysis,' Journal of Political Economy 87(3), pp. 479-500.

[6] Bardhan, Pranab K. (1983), 'Labor-Tying in a Poor Agrarian Economy: A Theoretical and Empirical Analysis,' Quarterly Journal of Economics 98 (3), pp. 501-14.

[7] Bardhan, Pranab K. (1991a), 'A Note on Interlinked Rural Economic Arrangements,' in P. Bardhan Ed. The Economic Theory of Agrarian Institutions, Clarendon, Oxford, pp. 237-42.

[8] Bardhan, Pranab K. (1991b), 'On the Concept of Power in Economics,' Economics and Politics 3, pp. 265-77.

[9] Basu, Kaushik (1986), 'One Kind of Power,' Oxford Economic Papers 38, pp. 259-282.

[10] Basu, Kaushik (1990), 'Agrarian Structure and Economic Underdevelopment,' Fundamentals of Pure and Applied Economics 37, Hardwood Academic Publishers.

[11] Bhaduri, Amit (1973), 'A Study in Agricultural Backwardness under Semi-Feudalism,' The Economic Journal, March 1973, pp. 120-37.

[12] Braverman, Avishay and Joseph E. Stiglitz (1982), 'Sharecropping and the Interlinking of Agrarian Markets,' American Economic Review 72 (4), pp. 695-715.

[13] Breman, Jan (1993), Beyond Patronage and Exploitation: Changing Agrarian Relations in South Gujarat, Oxford University Press, Delhi.

[14] Bell, Clive (1987), 'The Existence of Self-Enforcing Implicit Contracts,' Quarterly Journal of Economics 102, pp. 147-59.

[15] Craswell, Richard and Alan Schwartz (1994), Foundations of Contract Law, Oxford University Press, New York. 
[16] Daniel, Pete (1973), The Shadow of Slavery: Peonage in the South 1901-1969, Oxford University Press, New York.

[17] Dingwaney, Manjari, R. Vidyasagar and Anil Chaudhary (1986), Bonded Labor in India, Rural Labour Cell, New Delhi.

[18] Ennew, Judith (1981), Debt Bondage: A Survey, Anti-Slavery Society, Human Rights Series Report No. 4.

[19] Eswaran, Mukesh and Ashok Kotwal (1985), 'A Theory of Two-Tier Labor Markets in Agrarian Economies,' American Economic Review 75 (1), pp. 162-77.

[20] Government of India (1976), 'Bonded Labour System Abolition Act,' in Dingwaney, Manjari, R. Vidyasagar and Anil Chaudhary (1986), Bonded Labor in India, Rural Labour Cell, New Delhi, pp. 41-4.

[21] Hirshleifer, Jack (1991), 'Paradox of Power,' Economics and Politics 3 (3), pp. 177-200.

[22] Indian School of Social Science (1976), Bonded Labor in India, Indian Book Exchange, Calcutta.

[23] Kloosterboer, Willemina (1960), Involuntary Labour since the Abolition of Slavery: A Survey of Compulsory Labour Throughout the World, ed. by E. J. Brill, Leiden.

[24] Lasker, Bruno (1950), Human Bondage in South-East Asia, Chapel Hill, University of North Carolina Press.

[25] MacLeod, Bentley and James Malcomson (1989), 'Relational Contracts, Incentive Compatibility and Involuntary Unemployment,' Econometrica, vol. 57, pp. 447-80.

[26] MacMunn, George Fletcher Sir (1974), Slavery Through the Ages, E.P. Publishing Col (reprint of 1938 edition).

[27] Mukherjee, Anindita and Debraj Ray (1995), 'Labor Tying,' Journal of Development Economics, vol. 47 (2), pp. 207-39.

[28] Naqvi, Nadeem and Frederick Wemhöner (1995), 'Power, Coercion, and the Games Landlords Play,' Journal of Development Economics, vol. 47 (2), pp. 191-205.

[29] Prakash, S. S. (1990), Bonded Labour and Social Justice, Deep \& Deep Publications, New Delhi.

[30] Prasad, H. Pradhan (1976), 'Poverty and Bondage,' Economic and Political Weekly, August 1976 Special Number, pp. 1269-72.

[31] Prasad, R. R. and K. Suman Chandra (1994), Bonded Labourers: A Study of Rehabilitation and Organisational Dynamics, Har-Anad Publications, New Delhi. 
[32] Rosen, Sherwin (1985), 'Implicit Contracts: A Survey,' Journal of Economic Literature, vol. 23 (3), pp. 1144-75.

[33] Schaffner, Julie Anderson (1994), 'Attached Farm Labor, Limited Horizons and Servility,' Journal of Development Economics, vol. 47 (2), pp. 241-70.

[34] Shapiro, Carl and Joseph E. Stiglitz (1984), 'Equilibrium Unemployment as a Worker Discipline Device,' American Economic Review, pp. 433-44.

[35] Singh, Mohinder (1947), The Depressed Classes: Their Economic and Social Condition, Bombay.

[36] Srinivasan, T. N. (1989), 'On Choice among Creditors and Bonded Labour Contracts,' in The Economic Theory of Agrarian Institutions, edited by Pranab Bardhan,Oxford University Press, New York.

[37] Turton, B. (1976), 'Northern Thai Society,' Journal of Peasant Studies, vol. 3 (3).

[38] Watson, James Lee (1976), 'Servitude in Chinese Peasant Society,' Paper presented to the Center of International and Area Studies, University of London, London. 